\title{
Detection of Nanoscale Soil Organic Matter by Middle Infrared Spectrum for Forensic Science
}

\author{
Yingzi Liu, ${ }^{1}$ Qiang Li, ${ }^{2}$ Yumei Li, ${ }^{2,3}$ Jie Bao, ${ }^{2}$ Zhiheng Hu, ${ }^{2}$ Dakui Hao, ${ }^{4}$ \\ Dongxue Song, ${ }^{2}$ Yiwei Wang, ${ }^{2}$ and Min Yang ${ }^{2}$ \\ ${ }^{1}$ Department of Criminal Science and Technology, Shandong Police College, Jinan 250014, China \\ ${ }^{2}$ School of Biological Science and Technology, University of Jinan, Jinan 250022, China \\ ${ }^{3}$ Xinjiang Production \& Construction Corps Key Laboratory of Protection and Utilization of Biological Resources in Tarim Basin, \\ Alar 843300, China \\ ${ }^{4}$ School of Chemistry and Chemical Engineering, University of Jinan, Jinan 250022, China
}

Correspondence should be addressed to Yumei Li; mls_liym@ujn.edu.cn

Received 30 December 2014; Accepted 21 January 2015

Academic Editor: Jumin Hao

Copyright (C) 2015 Yingzi Liu et al. This is an open access article distributed under the Creative Commons Attribution License, which permits unrestricted use, distribution, and reproduction in any medium, provided the original work is properly cited.

Soil is useful as a kind of trace evidence for forensic science. Thus it is very crucial to identify sources of soil. The nanoscale soil organic matter (NSOMs) can be used to differentiate soil sources because their constituents and contents are relatively stable with time but variant by location. In this study, NSOMs from eighteen regions of Shandong Province in China were examined by middle infrared spectrum $\left(4000-400 \mathrm{~cm}^{-1}\right)$. The results showed that the constituents and contents of NSOMs in eighteen samples were dramatically different; a NSOM fingerprint for each sample was drawn based on these characteristics. This suggests that a national or global NSOM fingerprint database could be rapidly established by the one-step middle infrared spectrum analysis for different soil samples, which will be helpful to determine crime scenes by comparing the middle infrared spectrum of forensic soil with the NSOMs fingerprint database.

\section{Introduction}

Soil as important trace evidence can provide meaningful information for criminal investigation. The constituents of soil consist of organic matter, inorganic mineral grain, chemical precipitates (such as calcium carbonate and salt crystal), dead plants, animal matter, insect carapace, bacteria, soil algae, fungi, roots of higher plants, and so forth. Forensic detection of soil evidence has been performed by comparing soil components like organic matter, heavy and light minerals, oxides, stable and radioactive isotopes, pollens, diatoms, and microorganisms, meanwhile determining physical properties, such as color, distribution of particle sizes, and density [1]. Of these characteristics, the nanoscale soil organic matter (NSOMs) are the most easily affected by environmental factors, for instance, wreathing, microorganisms present in the soil, plants in nearby soil, animal residues, and artifacts of human beings [2]. This means soil from different places was discrepant. However, NSOMs are relatively stable in a period, which may give actual information from crime scenes.

The main constituents of NSOMs were composed of lignin, lipid or fatty acid, carbohydrate, protein, cellulose, hopane, and so forth [3]. The main functional groups of these compounds can be rapidly identified and quantified by middle infrared spectrum $\left(4000-400 \mathrm{~cm}^{-1}\right)$, which has become a powerful rapid assessment tool for determining soil properties [4]. In this study, eighteen soil samples from different regions in Shandong Province in China were selected and applied to Fourier transform infrared spectroscopy. Their NSOMs constituents (the main functional groups) and contents were rapidly and accurately determined. The results showed that there was a one-to-one relationship between the constituents and contents of NSOMs and the soil sources. Thus, a NSOM fingerprint was easily drawn, which suggests 
that it is possible to perform the rapid batch detections for a large number of soil samples to establish a national or global NSOM fingerprint database for forensic science.

\section{Materials and Methods}

2.1. Sample Collection. Eighteen soil samples were collected from different regions in Shandong Province in China. Samples were named as S1 to S18, representing Heze, Qufu, Zibo, Zhuangjia (Yantai), Penglai (Yantai), Zouping County (Bingzhou), Jiaxiang County (Jining), Kenli County (Dongying), Wulian County (Rizhao), Zaozhuang, Laiwu, Liaocheng, Rongcheng (Weihai), Jiaozhou (Qingdao), South Mountainous Area (Jinan), Taian, Changyi (Weifang), Xiajin (Dezhou), and Jining, respectively.

2.2. Sample Preparation. Soil samples were ground down into powder and dried at $120^{\circ} \mathrm{C}$ for 12 hours. Then $2.5 \mathrm{mg}$ of the dried soil sample was mixed with $500 \mathrm{mg}$ of dry potassium bromide $(\mathrm{KBr})$. The mixture was pressed into a mold $(8 \mathrm{~mm}$ in diameter and $0.05 \mathrm{~nm}$ in thickness) with a pressure of $1 \times$ $10^{8} \mathrm{~kg} / \mathrm{m}^{2}$.

2.3. Infrared Spectra. Infrared spectra were recorded in frequency ranges from 4000 to $400 \mathrm{~cm}^{-1}$ by a Fourier transform infrared spectroscopy (Bruker AXS VERTEX 70, Germany). The quantitative analysis of NSOMs was performed using KBr tablet method according to JJG-1996.

\section{Results and Discussion}

3.1. The Organic Spectra Peak Assignment. According to the previous investigation about the infrared spectra of soil organic matter (SOMs) [4-7], the peak assignments from S1 to S18 were analyzed. As shown in Figure 1, the peak assignment was varied with the soil source. The wide absorption peaks at 3591-3626 cm $\mathrm{cm}^{-1}$ were the characteristics of hydroxyl groups $(-\mathrm{OH})$. The small peaks at $3107-3448 \mathrm{~cm}^{-1}$ and $2322-2360 \mathrm{~cm}^{-1}$ were the characteristics of $-\mathrm{NH}$ and $\mathrm{NH}^{+}$, respectively. The peaks at $1612-1616 \mathrm{~cm}^{-1}$ belonged to $\mathrm{C}=\mathrm{C}$ stretching. The peaks at $1429-1635 \mathrm{~cm}^{-1}$ were attributed to $\mathrm{O}-\mathrm{N}=\mathrm{O} / \mathrm{C}=\mathrm{C}$ stretching. The peaks at $1379-1436 \mathrm{~cm}^{-1}$ were assigned to $\mathrm{C}-\mathrm{N}=\mathrm{O} / \mathrm{C}=\mathrm{O}$ stretching. The broad and intense stretching peaks at $1379-1384 \mathrm{~cm}^{-1}$ belonged to $\mathrm{C}-\mathrm{H}$ stretching. The peaks at $1006-1122 \mathrm{~cm}^{-1}$ were assigned to $\mathrm{C}-\mathrm{O}$ stretching. The peaks at $1000-1100 \mathrm{~cm}^{-1}$ and $1014-1024 \mathrm{~cm}^{-1}$ belonged to the characteristics of $\mathrm{P}-\mathrm{O}=\mathrm{R}$ and $\mathrm{C}-\mathrm{O}-\mathrm{C} / \mathrm{C}-\mathrm{O}$, respectively. The peaks at $740-779 \mathrm{~cm}^{-1}$ were associated with of $\mathrm{C}-\mathrm{O}-\mathrm{C}$ or $\mathrm{C}-\mathrm{H}$ stretching vibrations. The strong stretching peaks at $484-532 \mathrm{~cm}^{-1}$ and $469-457 \mathrm{~cm}^{-1}$ were attributed to $\mathrm{P}-\mathrm{Cl}$ and $\mathrm{C}-\mathrm{X}$ (halogen) stretching, respectively.

3.2. Quantitative Analysis. The numbers and types of the main functional groups in NSOMs of S1-S18 were analyzed according to the infrared data. As shown in Figure 2, the number, type, and absorbance value of the main functional groups in NSOMs varied with the source of the soil sample

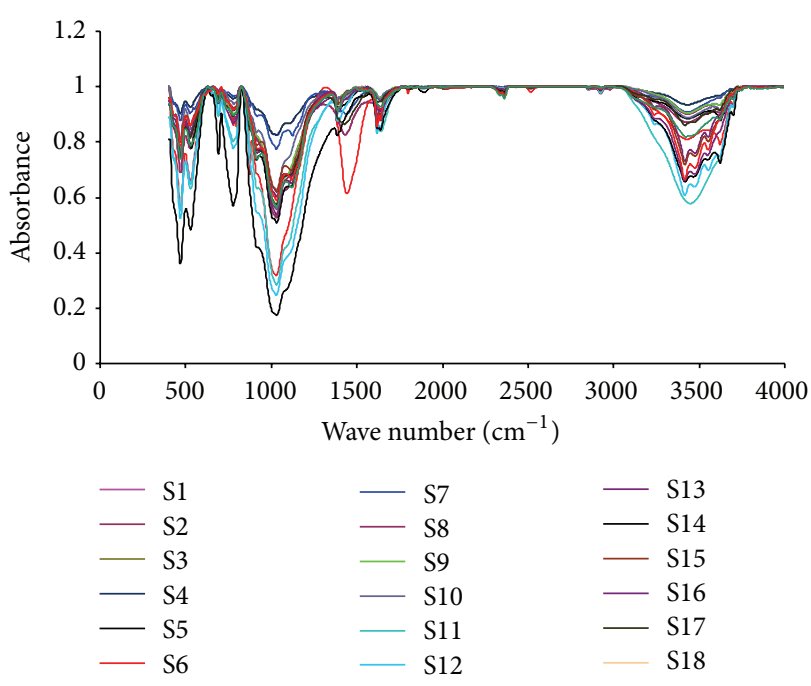

FIGURE 1: Infrared spectra of eighteen soil samples (S1 to S18).

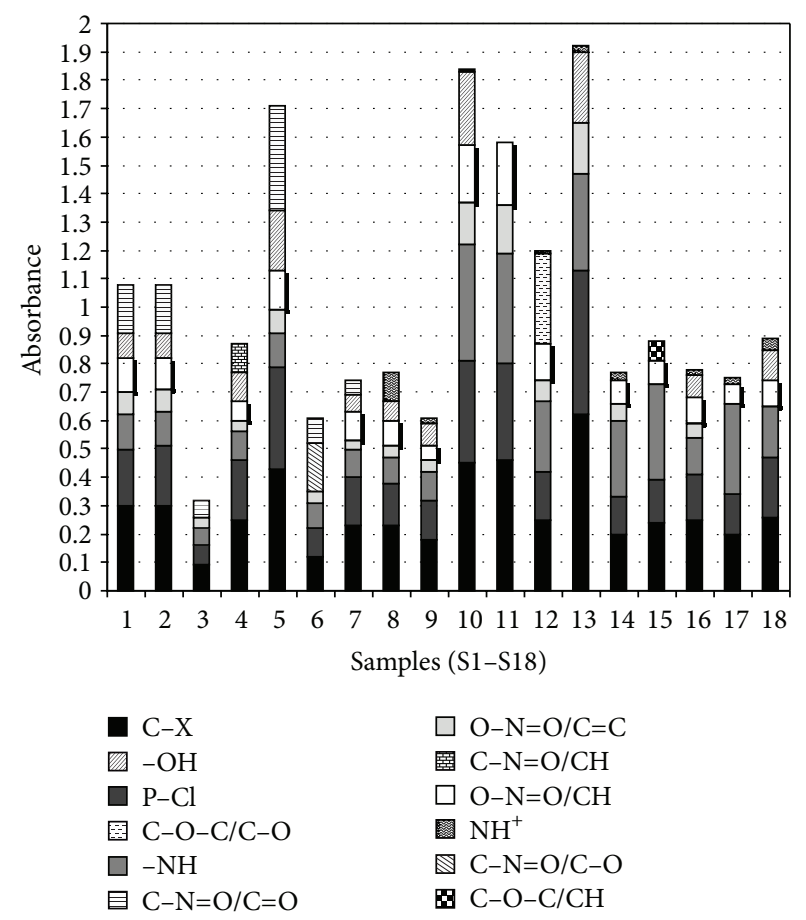

FIGURE 2: The number, type, and absorbance value of the main functional groups in NSOMs.

due to a variety of geological environments in different regions. The samples S1, S2, S4, S5, S7, S8, S9, S10, and S12 were composed of seven functional groups. S6, S13, and S18 consisted of six functional groups. S3, S11, S14, S15, and S17 contained five functional groups.

The hydroxyl group $(-\mathrm{OH})$ was present in all of 18 samples, but it was infinitesimal in S6, S15, S16, and S17. There were eleven types of functional groups in S18, which indicated that this sample contained abundant organic matter [8]. By contrast, S11 and S15 only contained seven types of functional 
TABLE 1: The database table design of S1 sample.

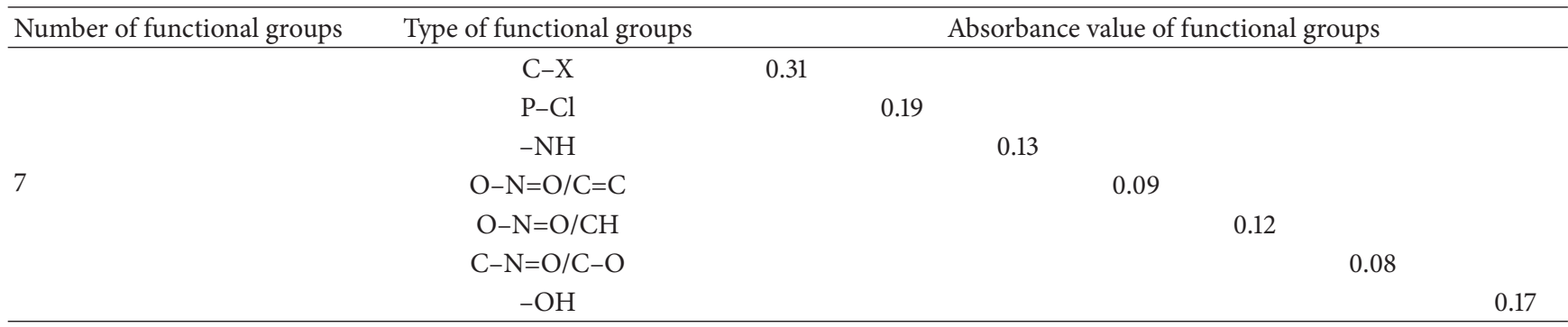

groups, which suggested that the organic matter were poor in these soil samples. The relative contents of $\mathrm{C}-\mathrm{X}$ and $\mathrm{P}-\mathrm{Cl}$ groups in S13 were highest in all of the samples, which were probably associated with the situated chemical plants in the sampling locations [9]. However, there were scarcely any C$\mathrm{X}$ and $\mathrm{P}-\mathrm{Cl}$ groups in S3, which meant that the soil of the sampling location was hardly contaminated [10].

The types of the main functional groups were only halfway similar for each sample. The absorbance value of the same functional group was different as well. These differences will be a favorable reference for the analysis of the soil source using a computer program.

3.3. NSOM Fingerprint Database. The SOM fingerprint database of tested soil samples (S1-S18) could be established according to the difference of the main functional groups in SOMs identified by the middle infrared spectra. The scheme of SOM fingerprint database was designed as follows: the database was created and named as A. Then a table, namely $\mathrm{B}$, was created in this directory, which contained some fields including number, type, and absorbance value of themain functional groups of NSOMs in each soil sample. Taking the table of S1 sample as an example, the procedure of the database table design was described (Table 1). Thus, the source of unknown soil sample may be rapidly identified using computer program through an SQL main organic functional groups query (SELECT * FROM TABLE B WHERE B.NumberOfKind = sample's number of kind AND B.Absorbance valueOftypel = sample's concent of typel AND...). This suggests that the establishment of the forensic SOM fingerprint database was feasible based on the infrared spectra analysis of SOMs, and the crime scenes will be rapidly locked using the forensic SOM fingerprint database.

\section{Conclusions}

In this study, Fourier transform middle infrared spectroscopy was applied to analyze eighteen soil samples from different regions of Shandong Province in China. The resulting infrared spectra showed that the constituents and contents of nanoscale soil organic matter (NSOMs) were varied with their sources. The main NSOM constituents of tested samples were composed of $-\mathrm{OH},-\mathrm{NH}, \mathrm{NH}^{+}, \mathrm{C}=\mathrm{C}, \mathrm{O}-\mathrm{N}=\mathrm{O} / \mathrm{C}=\mathrm{O}, \mathrm{C}-$ $\mathrm{N}=\mathrm{O} / \mathrm{C}=\mathrm{O}, \mathrm{C}-\mathrm{H}, \mathrm{C}-\mathrm{O}, \mathrm{P}-\mathrm{O}=\mathrm{R}, \mathrm{C}-\mathrm{O}-\mathrm{C}, \mathrm{O}-\mathrm{N}=\mathrm{O} / \mathrm{CH}, \mathrm{P}-\mathrm{Cl}$, and $\mathrm{C}-\mathrm{X}$ with different contents. Based on these characteristics, the NSOM fingerprints of tested soil samples were established, which could be useful for the rapid analysis of crime scenes by comparing the forensic soil with the NSOM fingerprint database.

\section{Conflict of Interests}

The authors declare that there is no conflict of interests regarding the publication of this paper.

\section{Authors' Contribution}

Yingzi Liu and Qiang Li contributed equally to this work.

\section{Acknowledgments}

This work was supported by the National Natural Science Foundation of China (Projects nos. 31300045 and 31100088), Foundation of University of Jinan (XKY1324), Open Fund of Xinjiang Production \& Construction Corps Key Laboratory of Protection and Utilization of Biological Resources in Tarim Basinand (BYBR1405), Shandong Province Science and Technology Development Plan (Grants nos. 2013GSF12006 and 2012GGB01172).

\section{References}

[1] P. Kenneth, Geological and Soil Evidence: Forensic Applications, CRC Press, 2007.

[2] L. A. Dawson and S. Hillier, "Measurement of soil characteristics for forensic applications," Surface and Interface Analysis, vol. 42, no. 5, pp. 363-377, 2010.

[3] R. J. Cox, H. L. Peterson, J. Young, C. Cusik, and E. O. Espinoza, "The forensic analysis of soil organic by FTIR," Forensic Science International, vol. 108, no. 2, pp. 107-116, 2000.

[4] N. C. Thanasoulias, E. T. Piliouris, M.-S. E. Kotti, and N. P. Evmiridis, "Application of multivariate chemometrics in forensic soil discrimination based on the UV-Vis spectrum of the acid fraction of humus," Forensic Science International, vol. 130, no. 2-3, pp. 73-82, 2002.

[5] C. Lee, T. M. Sung, H. S. Kim, and C. H. Jeo, "Classification of forensic soil evidences by application of THM-PyGC/MS and multivariate analysis," Journal of Analytical and Applied Pyrolysis, vol. 96, pp. 33-42, 2012.

[6] P. Smith, "Carbon sequestration in croplands: the potential in Europe and the global context," European Journal of Agronomy, vol. 20, pp. 229-236, 2004. 
[7] V. F. Melo, L. C. Barbar, P. G. Zamora, C. E. Schaefer, and G. A. Cordeiro, "Chemical, physical and mineralogical characterization of soils from the Curitiba Metropolitan Region for forensic purpose," Forensic Science International, vol. 179, pp. 123-134, 2008.

[8] T. Pan, M. Li, and J. Chen, "Selection method of quasicontinuous wavelength combination with applications to the near-infrared spectroscopic analysis of soil organic matter," Applied Spectroscopy, vol. 68, no. 3, pp. 263-271, 2014.

[9] R. N. Okparanma and A. M. Mouazen, "Visible and nearinfrared spectroscopy analysis of a polycyclic aromatic hydrocarbon in soils," The Scientific World Journal, vol. 2013, Article ID 160360, 9 pages, 2013.

[10] J. Wetterlind, B. Stenberg, and R. A. V. Rossel, "Soil analysis using visible and near infrared spectroscopy," Methods in Molecular Biology, vol. 953, pp. 95-107, 2013. 

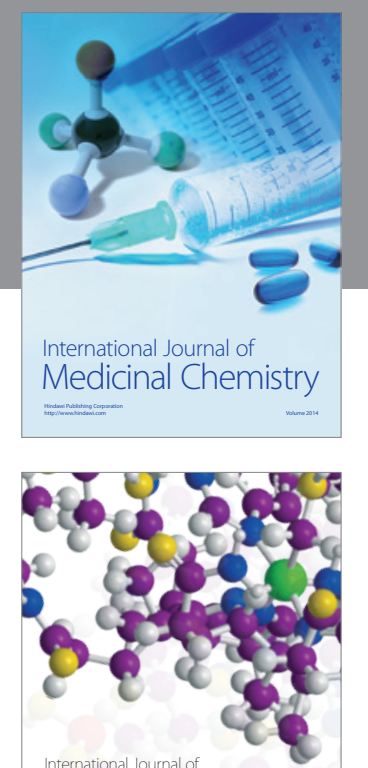

\section{Carbohydrate} Chemistry

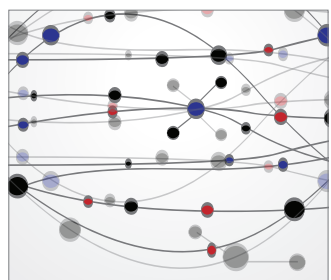

The Scientific World Journal
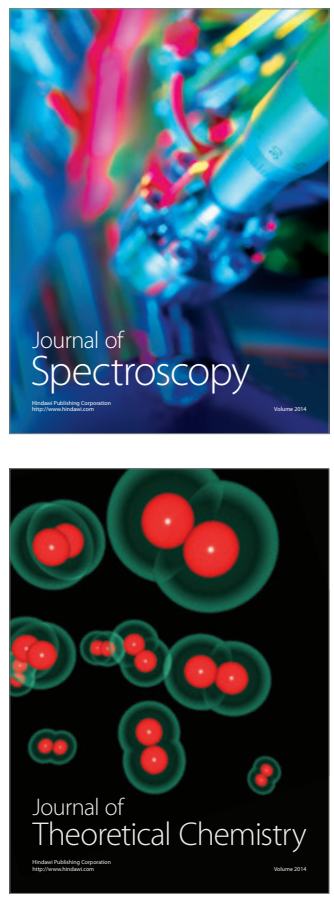
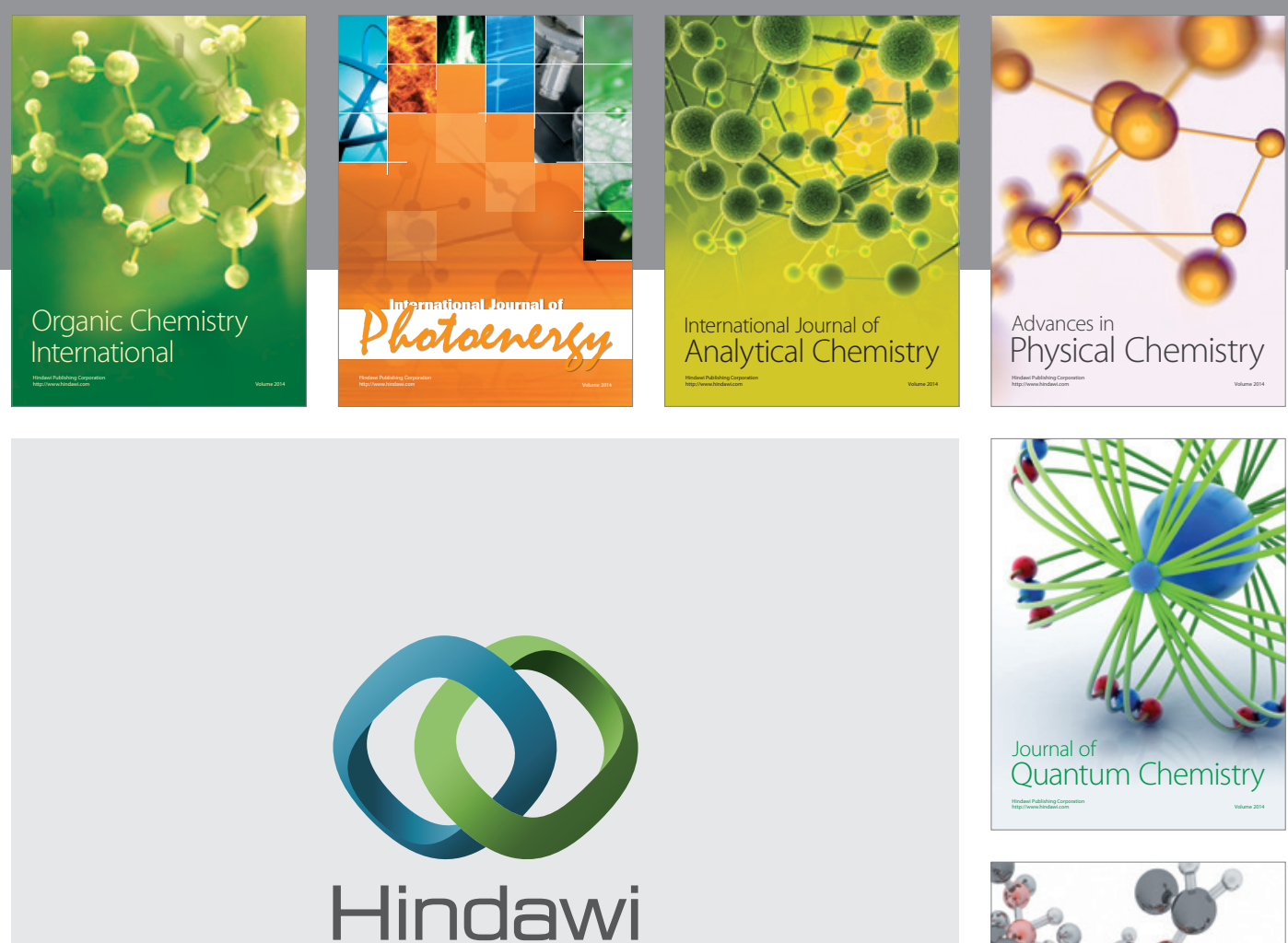

Submit your manuscripts at

http://www.hindawi.com

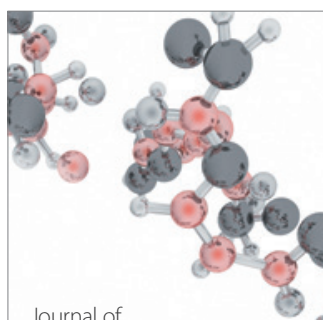

Analytical Methods

in Chemistry

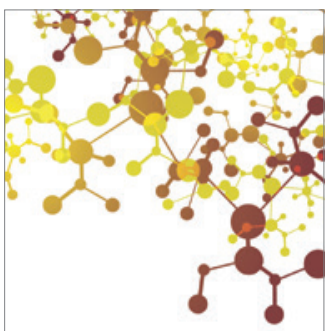

Journal of

Applied Chemistry

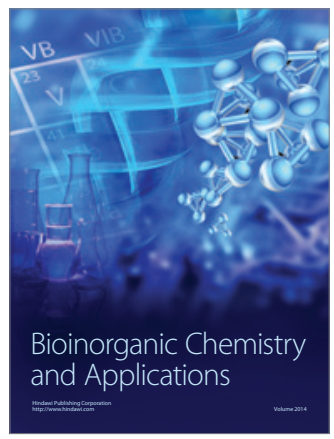

Inorganic Chemistry
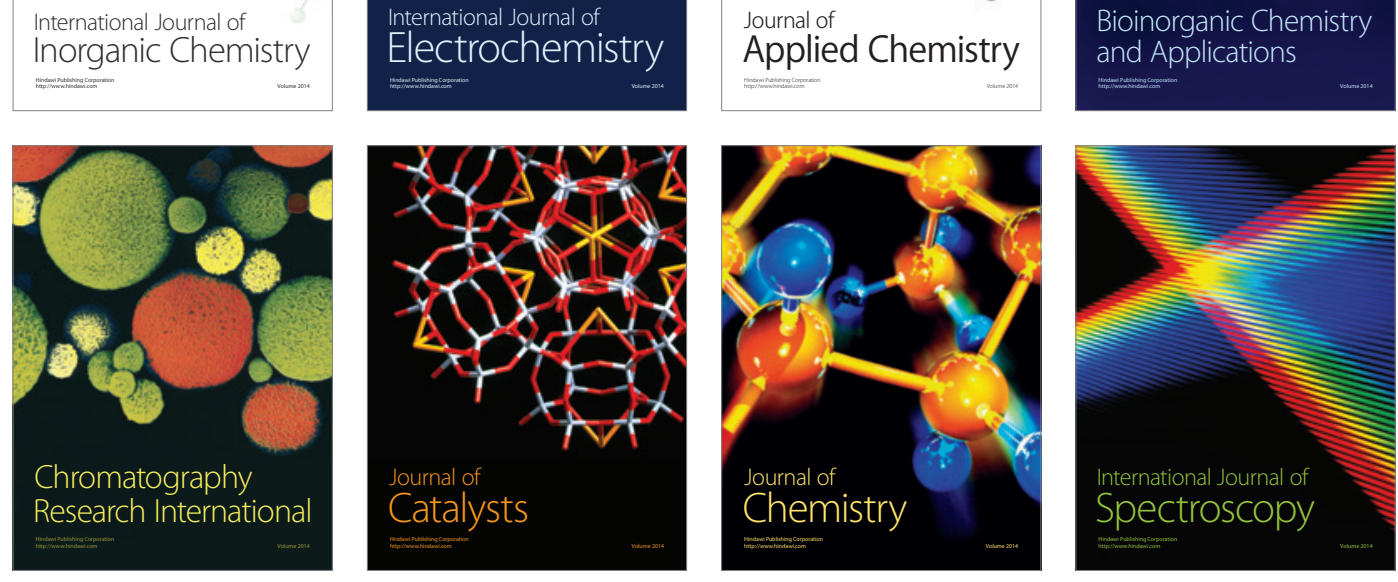